\title{
Les edicions catalanes del Pierres de Provença: estat de la qüestió*
}

\author{
The Catalan Editions of Pierres de Provença: State of the Art
}

\author{
Vicent Pastor Briones \\ vpb11@alu.ua.es \\ Universitat d'Alacant
}

Resum: La novel la anònima Pierres de Provença ens arriba des d'un original francès escrit a mitjan segle $\mathrm{XV}$ passant per algunes traduccions castellanes i catalanes que van fer-se des de principis del segle XVI. Malgrat la poca atenció que li ha dedicat la crítica literària en general, les aventures del cavaller Pierres i la gentil Magalona han comptat amb lectors de forma continuada fins al segle XIX. Aquest relat cavalleresc és un dels pocs títols que conformen el catàleg de la prosa impresa en català en l'època moderna, i és, per tant, força convenient fer una adequada catalogació de les edicions per tal de confegir un cens acurat que permeta estudiar l'obra i bastir-ne una edició crítica. Hem pogut establir un llistat d'onze edicions verificades pels bibliògrafs, de les quals només se'n conserven nou. La cronologia de les edicions és, a hores d'ara, aproximada, exceptuant-ne les que fan constar la data d'impressió a la portada: 1650, 1683 i 1908.

Paraules clau: Pierres de Provença, edicions, català, segles XVII-XVIII

\begin{abstract}
The anonymous novel Pierres de Provença has come to us from a French original written in the mid-fifteenth century through some of the Spanish and Catalan translations carried out since the beginning of the sixteenth century. Despite the little attention that it has received from most historians of literature, the adventures of the knight Pierres and the beautiful Magalona have had readers uninterruptedly up to the nineteenth century. This short chivalric story is one of the few works that make up the catalog of the Catalan prose of the modern period, and therefore it is quite convenient to make a thorough cataloguing of the editions made in order to establish an accurate census that allows to study the work and build up a critical edition. We have been able to establish a list of eleven editions verified by the bibliographers, of which only nine have been preserved. The chronology of most of the editions is, by now, just approximate, except those that have a specified date print on the cover: 1650, 1683 and 1908.
\end{abstract}

Keywords: Pierres de Provença, editions, Catalan, XVII-XVIIIth centuries

\footnotetext{
* Aquest treball és part de la nostra investigació per a una futura tesi doctoral, dirigida per la Dra. Marinela Garcia Sempere, que pretén enllestir una edició crítica del text català del Pierres de Provença a partir de tots els testimonis que hem estat capaços de recollir.
}

DATA PRESENTACIÓ: 18/02/2016 ACCEPTACIÓ: 25/05/2016 ·PUBLICACIÓ: 20/06/2016

SCRIPTA, Revista internacional de literatura $i$ cultura medieval $i$ moderna, núm. 7 / juny 2016 / pp. 52 - 69 


\section{Introducció}

El text que ací ens ocupa s'origina a la França de mitjan segle XV i recorre sis segles de vida atzarosa i prolífica en francés i, després, en nombroses llengües arreu d'Europa. L'anonímia autorial i la falta d'una datació exacta són problemes relacionats amb el text original: l'autoria atribuïda tradicionalment a un canonge del segle XII anomenat Bernard de Tréviers ja va estar descartada a finals del segle XIX; ${ }^{1}$ i és probable que el text fóra redactat entre 1430 i $1450 .^{2}$ Un altre problema és com classificar-lo dins un gènere concret: novel la cavalleresca breu, novel la sentimental, novel la hagiogràfica? Probablement, cal veure el Pierres de Provença com una narració cavalleresca breu en la qual l'element cavalleresc està poc desenvolupat per raons d'espai i d'economia editorial. Aquests aspectes són significatius perquè es podria dir que la novel la forma part d'un corpus de textos que es publicaren de forma continuada durant els segles XVI al XVIII seguint uns criteris comercials molt marcats, fins a l'extrem que es parla d'un gènere editorial (Infantes 1989: 120) més que no pas d’un gènere literari.

El nostre Pierres de Provença $a^{3}$ es presenta com la versió catalana d'una traducció castellana feta a principis del segle XVI. El fet de ser una traducció del castellà, derivada del francés o de l'occità, ${ }^{4}$ no li garantí gaires simpaties entre la crítica, que s'hi ha aproximat al text amb un desinterés quasi unànime, bandejant-lo de la majoria de les històries de la literatura catalana. Aquesta novel la sols apareix en uns pocs manuals, i quasi sempre només citada entre altres obres de prosa que els crítics han qualificat de ficció popular o narrativa de consum, ${ }^{5}$ i no com a objecte d'estudi per se. Amb prou feines podríem recollir informació original per a omplir un parell de fulls, partint, sobretot, de Rubió i Balaguer (1985: 229-230), el qual ens dóna algunes de les dades fonamentals. Amb tot, la seua fortuna editorial, si més no als segles XVII i XVIII, va ser força fecunda, però es va deixar d'imprimir durant més de cent anys fins que Ramon Miquel i Planas en va fer la seua edició el 1908, la darrera fins ara.

1 Gaston Paris (Romania, XVIII, 1889: 511). Malgrat el temps transcorregut des d'aquest desmentit, encara es pot llegir en les referències del Pierres de Provença de la Biblioteca de Catalunya o de la Biblioteca Nacional de España que l'autor és Tréviers.

2 Segons Babbi (2003: VI) i Roudaut (2009: 26-29) la major part d'hipòtesis datarien l'obra entre 1430 i 1450.

3 El títol complet és Història del noble y esforçat cavaller Pierres de Provença i de la gentil Magalona filla del rei de Näpols, i de les fortunes i treballs que passaren en la sua molt enamorada vida, segons apareix en l'edició de Sebastià Cormellas del 1650, la més antiga que es conserva.

4 François Roudaut (2009: 26) afirma, en la darrera edició francesa que s'ha fet de Pierres de Provence et la belle Maguelonne que, malgrat la possibilitat d'un text primitiu en provençal, del qual haurien derivat les primeres edicions, hi ha pocs elements que recolzen aquesta hipòtesi. Per tant, «la langue d'origine elle-même est incertaine».

5 Pel que fa a aquesta categorització, Valsalobre i Rossich (2011: 226-227) inclouen aquesta novel la junt amb l'Isopet, els Casos raros de la confessió, el Partinobles o el Llibre del romiatge del venturós pelegrí sota l'epìgraf "model de narrativa de consum, popularista".

SCRIPTA, Revista internacional de literatura i cultura medieval i moderna, núm. 7 / juny 2016 / pp. 52 - 69 
La història cavallerescosentimental de Pierres de Provença i la gentil Magalona es va estendre per tota Europa, de manera que se'n troben versions en anglés, castellà, català, italià, polonés, rus, etc., amb nombroses reimpressions, més o menys fidels o bé alterades. En el cas del castellà -llengua pont vers el català- comptem amb moltes edicions, ${ }^{6}$ i en català tenim un nombre total d'onze documentades, les quals plantegen alguns interrogants que cal resoldre, com ara l'existència d'una hipotètica primera edició (ca. 1538 ante quem) de la qual no se'n conserva cap exemplar. ${ }^{7}$

L'objectiu del present treball és, per tant, fer un cens de les edicions catalanes de la novel la Pierres de Provenç. El quadre 1 mostra el llistat de les edicions conegudes, excloent-ne les no catalogades de les quals només ens han arribat referències indirectes (ca.1538), les que presenten una falsa o doble datació (Rovira 1716 i segle XVIII) i les reimpressions (1908 Miquel i Planas, Fidel Giró). Per altra banda, tot i no ser una edició stricto sensu, hem decidit incloure la versió manuscrita que va fer Antoni Bulbena.

Quadre $1^{8}$

\begin{tabular}{|c|c|c|c|c|}
\hline DATA & LLOC & EDITOR & CÒPIES & UBICACIÓ \\
\hline 1616 & BARCELONA & S. CORMELLAS & 0 & BNF \\
\hline 1650 & BARCELONA & S.CORMELLAS & 1 & 0 \\
\hline 1670 & BARCELONA & A.LACAVALLERIA & 1 & Col lecció privada \\
\hline 1683 & BARCELONA & A.LACAVALLERIA & 1 & BC \\
\hline $1679-1705$ & BARCELONA & JOAN JOLIS & 1 & 5 \\
\hline $1668-1717$ & BARCELONA & RAFEL FIGUERÓ & BC- BNE - BLM-BMM \\
\hline $1751-1764$ & OLOT & JOSEP ROVIRA & 5 & BC - BLM- BMAR \\
\hline $1751-1771$ & OLOT & JOSEP ROVIRA & 1 & BUT \\
\hline $1703-1768$ & GIRONA & JAUME BRO & 3 & BC - BNE - AB \\
\hline $1703-1768$ & GIRONA & JAUME BRO & 3 & BC \\
\hline 1895 & BARCELONA & ANTONI BULBENA & 1 & DD.LL. \\
\hline 1908 & BARCELONA & MIQUEL I PLANAS/ & & \\
\hline
\end{tabular}

6 Per a un inventari complet de les edicions fetes en diferents llengües, vegeu Babbi (2003: 267-296).

7 Aquesta podria derivar bé de les cinc edicions castellanes aparegudes entre 1519 i 1533, bé de les vora trenta edicions franceses aparegudes des de 1480, en el cas que foren traduccions directes. Ara bé, si partim de la de 1650, Honorat Comalada tenia 9 edicions castellanes a l'abast per fer-ne la traducció al català -sense descartar que ell fóra l'autor de la traducció de 1616. El nombre d'edicions franceses vorejava la cinquantena ja aleshores.

8 Donem com a dates contrastables només les de Cormellas 1650, Lacavalleria 1683, Antoni Bulbena 1895 i Miquel i Planas 1908 (Annex 1); la resta són les dates aproximades - deduïdes dels anys d'activitat dels impressors-aparegudes en els articles consultats, catàlegs bibliogràfics i les referències que donen les biblioteques, que no ens semblen satisfactòries. Pel que fa a la ubicació que oferim al quadre: BNF (Biblioteca Nacional de França), BC (Biblioteca de Catalunya), BLM (Biblioteca Lambert Mata de Ripoll), BNE (Biblioteca Nacional de España), BNA (Biblioteca Nacional d’Àustria), BMM (Biblioteca Municipal de Montpeller), BMAR (Biblioteca de Marsella), BUT (Biblioteca de la Universitat de Tolosa de Llenguadoc), AB (Ateneu Barcelonès), DD.LL. (Diverses localitzacions). 
Tan sols les edicions de 1650, 1683, 1895 i 1908 vénen amb la data a la portada; els colofons no aporten cap informació útil al respecte en cap de les edicions. Les edicions sense datació convincent són moltes i, encara que algunes monografies -com ara Camprubí (2014)- estan aportant dades sobre els impressors dels segles XVII i XVIII relacionats amb el Pierres de Provença, ens manca molta informació sobre Antoni Lacavalleria, Joan Jolis, Rafel Figueró i Jaume Bro.

Aquest tipus de publicacions de consum popular ${ }^{9}$ ha estat subjecte a una gran volatilitat i, per aquesta raó, l'investigador sovint troba poques mostres que ens hagen pervingut. De tots els catàlegs bibliogràfics consultats, els més profitosos per a aquest treball han estat els d'Aguiló (1874), Simón Díaz (1954) i Palau Dulcet (1961). També hem consultat Torres Amat, Gayangos, Gallardo, Miquel i Planas i Rubió i Balaguer.

\section{Les edicions del segle $X V I^{10}$}

Parlar d'edicions del Pierres de Provença al segle XVI és especular sobre referències de textos perduts. De la que es degué fer abans de 1538 no tenim cap altra notícia que la que ens dóna Rubió i Balaguer (1985: 229-230): «A linventari de la llibreria Cabrit, de Barcelona, formalitzat el 1538, i també el 1552 en el magatzem del llibreter Pi, apareixen nombrosos plecs, en rama, contenint "Magalonas en pla”, és a dir, en català». ${ }^{11}$ Rubió i Madurell van publicar aquest inventari que havia estat descobert per Ernest Moliné i Brasés, del qual donava notícia en el seu llibre Llibreters barcelonins del segle XVII: Cabrit: Trinxer. ${ }^{12}$ Rubió es planteja si la traducció de la història de Pierres de Provença que ens ha

9Jordi Rubió i Balaguer (1955: 103) fa aquesta reflexió sobre la consideració social, malgrat l'èxit entre els lectors, que tenien al segle XV obres com el Pierres de Provença: «Pero la literatura menos tradicional, la de actualidad de un día, en prosa y en verso, tanto en romances como en cobles, tenía tan poco precio en el mercado y en la futura almoneda, que los notarios la dejaban a un lado al formalizar un inventario o la concentraban para el remate bajo un título que bastante indicaba el poco aprecio que de ella se hacía. Eran las menudències... de poca calitat de las que nos habla el inventario de la librería de Timoneda en Valencia en 1583. A medida que avanza el siglo XVI, esta producción parece cobrar mayor atención, porque debía de ser cada vez más numerosa».

10 Sobre la producció editorial en català des del segle XVI al XVIII, Garcia \& Wilkinson (2011: 64), afirmen que només es publica en català un 12\% de la producció entre 1560 i 1600; Llanas (2001: 30-35) parla d'una producció impresa en català al segle XVII de poc més d'un 10\% del total de llibres impresos, i al XVIII un minso 5\% a la ciutat de Barcelona a la primera meitat del segle, en oposició al 21\% a Girona tot al llarg de la centúria

11 Per la seua part, M. Llanas (2002: 99) xifra l'inventari de Cabrit en 160 llibres, bàsicament llibres escolars i llibres populars de consum, ja foren d'oració o de ficció.

12 A partir de les notícies que aporta Moliné (1918: 9-16), Rubió i Madurell (1955: 787-797) inclouen l'inventari com a document 455. De l'inventari (9 -12-1538) ens interessen aquests ítems: 31 Item vuyt llibres donsella Magalona en pla sens ligar, 67 Item bun plech en què ha quatre mans sis mans Maglones y lunaris; 109 Item bun plech son una rayma Magalones; i 147 Item hun plech en què ha sinch Libres Magalona y set lunaris tot cusit. Pel que fa al llibreter Pi, al document 505 (p. 889-891) apareixen "Vint raymes Magalonas". 
arribat era un simple arranjament a partir d'una versió catalana perduda i no pas una traducció de la versió en castellà, adduint que el text català no "té deixis de castellanismes i els seus arcaismes no són propis d'una redacció del XVI". ${ }^{13}$ Aquest estudiós ja sostenia molt abans (1955: 796) que novel les com el Pierres: «Eran obritas de surtido, de corta extensión y de las que había ejemplares en existencia. Esto mismo me hace creer que la edición era en catalán, aunque hoy la más antigua conocida en nuestra lengua sea del XVII». ${ }^{14}$ Aquesta és tota la informació de què disposem sobre una possible primera edició catalana coetània de les castellanes aparegudes durant el primer terç del segle XVI. ${ }^{15}$ A més, de confirmar-se les conjectures de Rubió i Balaguer, Honorat Comalada, únic traductor conegut al català, podria haver tingut a l'abast una traducció catalana prèvia sobre la qual hauria pogut treballar. ${ }^{16}$

\section{Les edicions del segle XVII}

El món editorial del segle XVII a Catalunya (Llanas 2001: 30) ens mostra una producció marcada per una forta tendència a la temàtica religiosa -més del 40\% del total-, i als plecs solts poètics associats a la literatura de canya i cordill de consum massiu. Sovintegen els tiratges d'entre mil i tresmil exemplars. Per altra banda, la profunda castellanització de la producció impresa culta del segle anterior continua i el català queda relegat fonamentalment als gèneres menors. En conjunt, dels mil llibres publicats al llarg del segle a Catalunya, només 112 ho foren en català. És en aquest context editorial on cal situar les primeres edicions conservades ${ }^{17}$ del Pierres de Provença ja en l'època barroca. A hores d'ara, tot seguint Miquel i Planas, cal remetre'ns a l'edició que va fer Sebastià Cormellas el 1650 a Barcelona, primera conservada completa, sense perdre de vista la mutilada de 1616, que ell havia vist i que haguera preferit -en cas d'estar completa- sobre l'emprada per ser anterior i donar

13 La llengua que trobem a l'edició de 1650 no sembla ser la pròpia del seu temps car hi podem trobar formes verbals com ara dix, afirmatius com hoc o possessius com les sues, que ens retrotrauen a un estadi de la llengua que semblaria més adient a les acaballes del segle XV.

14 Insisteix en la mateixa idea quan parla dels gustos lectors de la Barcelona del segle XVI: «És veritat que no falten, ni de bon tros, citacions de Paris i Viana, Pierres de Provença, Melusina i Partinoples. En grans paquets, en raimes de vegades, es trobaven a les prestatgeries de les botigues dels llibreters» (1993: 181).

15 Burgos 1519, Sevilla 1519, Burgos 1521, Toledo 1526 i Sevilla 1533.

16 Albert Rossich (2010: 161), parlant de novel les en voga al segle XVI, fa referència al Pierres de Provença: «S’hi van afegint d'altres, de les mateixes característiques, que no trobem documentades explícitament en la seva hipotètica versió catalana medieval (el Pierres de Provença, el Partinobles), però que la impremta anirà divulgant [...]».

17 Gayangos (1857: LXXXI) dóna notícia -tot seguint Brunet- d'una edició de 1600, però probablement es referia a la de 1616. El que sí que ens interessa és el títol, per quant presenta petites diferències respecte del de 1650: La bistoria del cavaller Pierres de Provença fill del conte de Provença y de la gentil Magalona filla del rey de Napoles, traduida de llengua castellana en la llengua catalana per Honorat Comalada.

SCRIPTA, Revista internacional de literatura i cultura medieval i moderna, núm. 7 / juny 2016 / pp. 52 - 69 
una millor lliçó. Nogensmenys, ens cal considerar aquesta com la primera de les edicions de l'obra:

1) 1616 Podríem suposar que l'edició fou obra de Cormellas perquè del seu taller ja n'havia eixit una edició en castellà el 1600, i també ix del seu taller la de 1650. La manca d'exemplars que ho verificaren va restar credibilitat durant un temps a la primera referència a aquesta edició, que donà l'erudit religiós Fèlix Torres i Amat (1836: 184): ${ }^{18}$ «COMALADA (Honorato). Tradujo del castellano al catalan la historia del Cavaller Pierres de Provensa, y de la donsella Magalona. Barcelona 1616 en $8^{\circ}$ ». La veracitat de l'existència d'aquesta primera edició la va poder comprovar Ramon Miquel i Planas quan el bibliòfil català Joaquim Montaner i Malató va posar a la seua disposició dos exemplars de la novel la: un de l'edició de 1616 i l'altre de la de $1650 .{ }^{19}$ La descripció que en fa Miquel i Planas (1908: XVI) és la següent: «mancat de portada y d'algunes fulles de l'interior del llibre $[1,2,8,9,16,17,22,24,25,26]$, ens aparegué tot seguit com de la edició de 1616». Parla l'editor, a més, d'altres aspectes que permeten validar la data: l'aspecte tipogràfic, que li sembla més primitiu que el de l'edició del 1650, i algunes petites particularitats ortogràfiques. Segons Miquel i Planas, totes les edicions posteriors reprodueixen les errades de la de 1650, o les salven com poden. De la qual cosa dedueix que la millor lliçó és «la de l'exemplar mutilat que atribuïm a 1616», raó per la qual quan edita la novel la segueix el text de 1650 però sense perdre de vista el de 1616. En referència a la descripció física de l'exemplar, l'única diferència amb el que diu Torres Amat és que l'exemplar trobat no és en octau sinó en quart (120 x 185 mm. de caixa). No li dóna gaire importància, tot disculpant el possible error de Torres Amat, perquè el llençat o compaginació és de 16 pàgines per signatura, i això podria haver-li donat a entendre al bibliògraf que li esqueia la qualificació de format en octau, sense atendre a les dimensions físiques. Pel que fa a d'altres elements, Miquel i Planas afig una mostra de dos dels petits gravats intercalats «(no'ns atrevím a dir-ne ilustracions perque més aviat semblen boixos aprofitats d'estampacions diverses)», que apareixien en ambdues edicions, i no pas en cap de les posteriors:

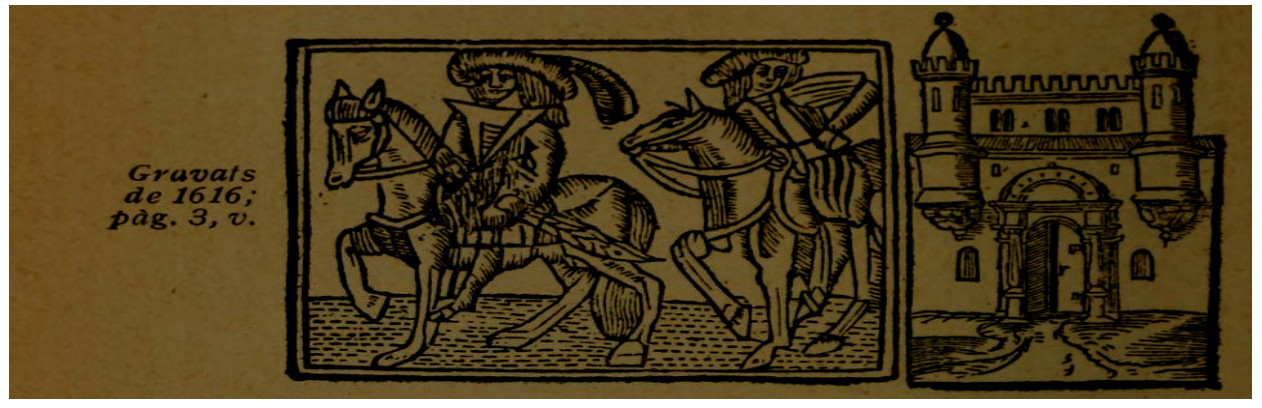

$18 \mathrm{Al}$ respecte, Palau Dulcet (1961, XIII: 225) diu: «Repetimos que nada sabemos de las primeras ediciones hechas en España de este libro popular. La más antigua de que se tiene noticia en lengua catalana es la de Barcelona, 1616, $4^{\circ}$, citada por Torres Amat. Actualmente no se conoce ningún ejemplar completo; solamente el ejemplar de Joaquín Muntaner que vió Miquel y Planas de 31 folios falto de portada y algún folio, podría ser de aquella edición, pero de fijo que habrán desaparecido otras ediciones anteriores».

19 Malauradament no hem pogut esbrinar què se’n va fer de la col lecció de Montaner i, en conseqüència, no disposem de cap notícia sobre el parador actual d'aquests dos textos.

SCRIPTA, Revista internacional de literatura i cultura medieval i moderna, núm. 7 / juny 2016 / pp. 52 - 69 ISSN: 2340-4841 · doi:10.7203/SCRIPTA.7.8055 


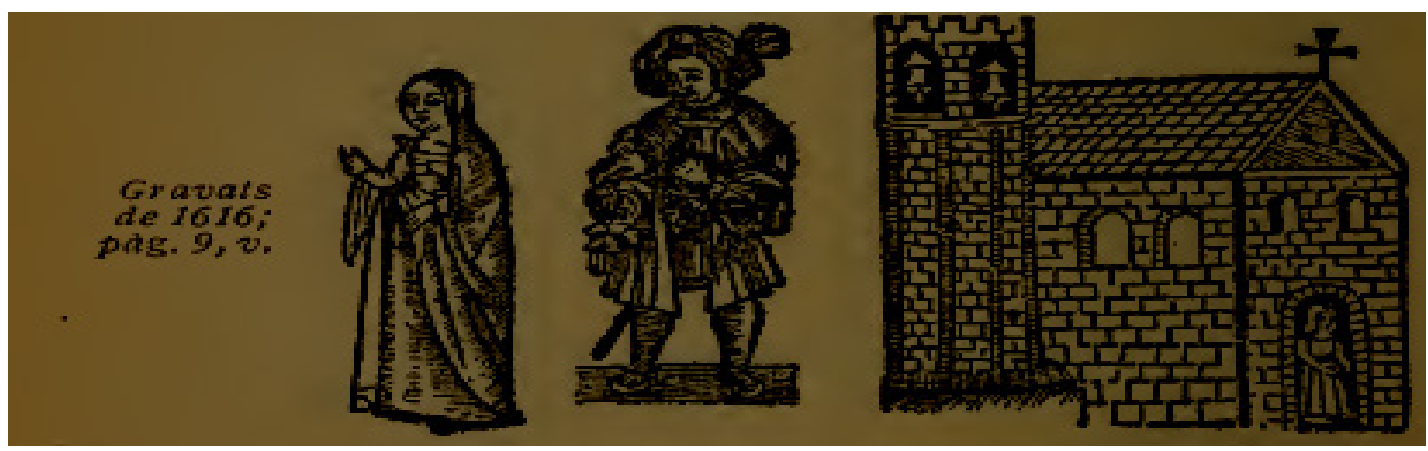

2) Cormellas $1650^{20}$ Ací comença / la bistòria del noble, y/ esforçat Cavaller Pierres de Prouença, fill del / Comte de Provença. Y de la gentil Magalona, / filla del Rey de Näpols; y de les fortunesy treballs que passaren en la sua molt/ enamorada vida./ Traduj̈da de llengua Castellana, en nostra llengua Catalana, per lo discret y honrat Honorat Comalada. L'edició de Sebastià Cormellas continua essent, doncs, el text base sobre el qual treballar, tal com va fer Miquel i Planas. Com hem dit més amunt, aquest afirmava haver fet una mena d'edició conjunta prenent com a base el text complet de 1650: reprodueix puntualment l'edició de Cormellas, però empra l'anterior (1616) per millorar-la en aquells punts on el segon text sembla haver-se apartat de l'original.

Sembla que només s'ha conservat d'aquesta primera edició de 1650 l'exemplar de la BNF (RES-Y2-710). L'única informació física que tenim sobre aquest exemplar és que està editat en quart, de 32 fulls (64 pàgines), amb caplletres ornades. La portada representa un cavaller amb espasa i una dama, ambdós semblen eixits d'una escena de novel la tardomedieval. Hi ha gravats intercalats a l'inici dels capítols I, III, IV, V, VII, IX, XI, XIII, XV, XXII, XXVI, XXIX, XXXI i XXXIII, sempre a continuació del títol del capítol.

Sobre el "discret y honrat" traductor Honorat Comalada, ${ }^{21}$ les poques fonts disponibles ens parlen d'un escriptor que va viure a cavall dels segles XVI i XVII, sense cap precisió biogràfica. Sol aparéixer com a traductor del Pierres de Provence et de la belle Maguelonne francés al català a partir d'una traducció castellana anterior, impresa a Barcelona, probablement el $1600 .{ }^{22}$ La primera notícia és, però, la que ens donava Torres Amat en parlar de l'edició de $1616 .{ }^{23}$ Pel que fa a l'impressor,

20 Referències bibliogràfiques: Gallardo, I, 873; Aguiló 2762; Miquel i Planas (1908: XIX-XX), i així per a la resta d'edicions que hi recull; Simón Díaz 7488; Palau, XIII, 225640.

21 Diccionari de literatura de la Enciclopèdia, p. 270.

22 Wilkinson (2010: 655) no la recull.

23 Parlant de les traduccions del Pierres de Provença, Gayangos, ibíd., desmenteix l'afirmació de Nicolás Antonio, segons

SCRIPTA, Revista internacional de literatura i cultura medieval i moderna, núm. 7 / juny 2016 / pp. 52 - 69 
sabem que Sebastià Cormellas López (ca. 1563-1636) ${ }^{24}$ és un pes pesant del món editorial entre el canvi de segle XVI i principis del XVII. Pare i fill homònims, els Cormellas van treballar de forma ininterrompuda al carrer del Call, 14, des de 1591, però sembla que el fill, Sebastià Cormellas Velasco (ca.1590-1667) va iniciar la seua producció vers el 1638, probablement arran de la mort de son pare, fins al 1664. Entre els dos van imprimir ${ }^{25}$ més de 250 títols, el $90 \%$ dels quals de temàtica religiosa, però també d'altres temes, amb títols tant d`obres populars com cultes. El gruix de la producció la va dur a terme Cormellas pare com ho prova el fet que es conserven uns trescents títols al Catàleg Col lectiu de les Universitats de Catalunya (CCUC) produïts abans de la mort d'aquest, mentre que dels impresos entre 1636 i 1666 pel fill no en queden més de seixanta. Josefina Mateu (1994: 239), seguint Agustín Millares, ${ }^{26}$ ofereix un llistat de seixanta-quatre obres eixides del taller Cormellas entre 1591 i 1600. El bloc literari inclou dèsset títols, cap dels quals en català, on hi destaca La historia del cavallero Pierres de Provença y la gentil Magalona, filla del Rey de Napoles, datada el 1600, segons referència bibliogràfica de Gayangos. ${ }^{27}$ Pel que ara ens ocupa, M. Llanas (2002: 276) confirma que Cormellas pare havia enllestit una Historia del caballero Pierres de Provença en versió castellana datada el 1600. Aquesta notícia ens fa pensar que Cormellas li podria haver oferit aquest text castellà anterior a Comalada perquè el traslladara al català el 1616, encara que també podria tractar-se d'un text diferent ja existent. Tampoc sabem si Comalada va estar l'autor d'una traducció prèvia del francés al castellà.

Les següents edicions van sortir dels tallers barcelonins d'Antoni Lacavalleria: ${ }^{28}$

3) Lacavalleria $1670^{29}$ Només en coneixem l'incipit. Asi comença la historia del noble, y esforçat cavaller Pierres de Provença. D’aquesta edició, malgrat que en donen notícia Aguiló, Simón Díaz i Palau Dulcet, tan sols sabem que tenia 28 fulls en quart. No hi ha rastre de cap exemplar.

4) Lacavalleria 1683 La historia del noble, y esforsat Cavaller Pierres de Provença, y de la gentil Magalona filla del Rey de Napols, y de les fortunes y treballs que passaren en la sua molt enamorada vida.

la qual Felipe Camus va traduir la novel la francesa al castellà. Segons Gayangos, Camus va ser un escriptor francés que va traduir del castellà al francés vàries obres populars, com ara l'Oliveros i d'altres.

24Manuel Llanas, Els Cormellas (http://lletra.uoc.edu/ca/autor/els-cormellas) [Consulta: 17-6-2015] i Pere Bohigas (1962: 224).

25 El fill no va treballar mai d'impressor i es dedicà a d'altres activitats mercantils. (X. Camprubí, 2014: 576).

26 «La imprenta en Barcelona en el siglo XVI», dins Carlos Romero de Lecea (1982) Historia de la imprenta hispana, Madrid: Editora Nacional, p. 491-643.

27 Millares va fer una lectura errònia de Gayangos (1857: LXXXI) perquè confon el títol amb una possible versió en castellà (vid. nota 20).

28 J. Delgado Casado (1996: 364-365) recull l'edició de 1670, però no pas la de 1683. Pere Bohigas també en fa esment (1962: 224).

29 Referències bibliogràfiques: Aguiló 2673; Simón Díaz 7489; Palau Dulcet, XIII, 225641.

SCRIPTA, Revista internacional de literatura $i$ cultura medieval $i$ moderna, núm. 7 / juny 2016 / pp. 52 - 69 
Tradubida de llengua castellana, en la nostra Catalana, per lo discret, y honrat Honorat Comalada. Menys enigmàtica resulta aquesta segona edició de Lacavalleria, ${ }^{30}$ de 56 pàgines en quart, de la qual Aguiló en descriu un exemplar complet, però en mal estat. ${ }^{31}$ La referència més recent a aquesta edició ens informa d'un exemplar sense enquadernar, conservat en cartera de pergamí, que mesura $20^{\prime} 5$ x $15^{\prime} 5$ cm., i que pel moment no es pot consultar. ${ }^{32}$

Sobre l'impressor Antoni Lacavalleria Dulach sí que se'n té bona notícia en tant que membre d'una de les nissagues editorials més reconegudes, iniciada per son pare Pere Lacavalleria. Del carrer Llibreteria estant, la seua tasca s'estengué entre 1646 i 1700, dedicada fonamentalment a la literatura religiosa, però també cal destacar la important producció de plecs poètics solts, que constituïen la literatura anomenada de canya i cordill de gran difusió, si bé que, generalment, de poca qualitat literària. En aquest sentit cal entendre la reedició del Pierres el 1670, any que obri la dècada més fructífera d'aquest taller. ${ }^{33}$ J. Pascual (1985: 611), en descriure la producció de Lacavalleria, fa la següent observació: «Obligatorio es incluir también los librillos populares y caballerescos, cual el Pierres de Provença, o el Partinobles, que integran buena parte del Novel tari de Miquel y Planas [...]». Més avant (p. 626-627) ens informa que, segons una ordre de 1655, el preu taxat per a aquests llibres era de 2 lliures i 6 sous tant per a "Una Magalona" com per a "Un Comte Partinobles". A més, hi explica l'èxit d'aquestes «novelitas de cordel, populares como el Pierres de Provença, que como era de esperar renacía varias veces en las prensas de nuestro impresor».

La següent edició és obra de Joan Jolis:

5) Jolis 1679-1705 ${ }^{34}$ Història del noble y molt esforsat cavaller Pierres de Provensa, y de la gentil Magalona filla del rey de Napols, y de les fortunes, y treballs, que passaren en lo temps de la sua enamorada vida. Tradubida de llengua Castellana en la nostra Catalana, per lo discret, y honràt Honoràt Comalada. Aquesta és la primera edició de la qual en tenim localitzat un exemplar complet al domini lingüístic català

30 Referències bibliogràfiques: Aguiló 2674; Simón Díaz 7490; Palau, XIII, 225642.

31 Catálogo... p. 662: «La he visto por conducto de D. José Palau Huguet. La posee un farmacéutico de San Feliu de Llobregat. Es mal ejemplar, aunque completo, y conserva la ortografía antigua».

32 De manera casual vam trobar que la llibreria antiquària asturiana Galgo de Granda-Siero (catàleg 52, setembre 2005: http://www.libreriagalgo.com/descargapdf.php?pdf=17.pdf) treia a la venda aquest exemplar. El susdit catàleg ens aporta informació sobre el document i la imatge de la portada; el llibre estava a la venda per dos mil euros. I sabem que, posteriorment, un comprador anònim el va adquirir.

33X. Camprubí (2014: 627) explica com tot el material d'imprimir del taller va ser venut pels hereus l’any 1706 a Rafel Figueró.

34 La datació que proposa la BC és ca. 1690. Les altres referències bibliogràfiques són Miquel i Planas (1908: XIX-XX), que no dóna cap data, i Palau (XIII, 225642), que indica que és de finals del segle XVII. Rodríguez Cepeda (1984:19) l'atribueix al fill, Joan Jolis Oliver, i la data al voltant de 1710. Segons Camprubí (2014: 706) seria la vídua i no pas el fill, aleshores menor d'edat, qui n'estava al càrrec fins l'any 1722. Després d'aquest any el fill se n'ocupà fins a la seua mort el 1759 però en cap moment es canvià el nom del negoci, fet que dificulta encara més fixar una possible data. 
i a l'abast de tothom, a la Biblioteca de Catalunya, dins la Col lecció Bonsoms-Chacón (Bon.9II-30). La referència completa informa que la data és aproximada i deduïda de l'època de treball de l'impressor Joan Jolis. La descripció física parla d'un exemplar en quart, de 56 pàgines, amb un gravat a la portada, a més de frisos i caplletres ornades i reclams; l'exemplar està enquadernat en pell, i presenta taques d'òxid.

Sobre l'impressor i gravador Joan Jolis Santjaume (Sant Feliu de Torelló, 1650 - Barcelona, 1705), sabem que el 1676 es va instal lar al carrer de Cotoners a Barcelona, on edità diversos llibres almenys entre 1679 i $1704 .{ }^{35}$ Encara que va destacar més com a gravador que com a impressor, la seua producció arribà als seixanta llibres (Socias Batet 2001: 23-25), repartits de manera desigual al llarg dels vint-i-cinc anys d'activitat, amb una mitjana de tres per any. Del conjunt publicat només sis llibres -incloent-hi el Pierres- ho foren en català. Va treballar fonamentalment amb plecs solts -goigs, plecs poètics-, i en general impresos menors. A més del Pierres, també va imprimir un Partinobles en castellà.

\section{Les edicions del segle XVIII}

Quant a les edicions del Pierres de Provença en aquest segle, comencem plantejant un dubte: és ací on cal situar l'edició que va fer Rafael Figueró? O aquesta edició és de finals del XVII? Nosaltres proposem una possible nova datació: ${ }^{36}$

6) Figueró 1668-1717 La historia del noble, y esforsat Cavaller Pierres de Provença, y de la gentil Magalona filla del Rey de Napols, y de las fortunas, y treballs, que passaren en la sua molt enamorada vida tradubida de llengua Castellana en la nostra Catalana, per lo discret, y honrat Honorat Comalada. La datació que ens ofereix la BC és desafortunada [19..?]. La BMM i la BLM ens proporcionen una data incompleta, però més probable: 16.. . Per la seua banda, la BNE la data entre 1669 i 1722, deduïda a partir dels anys d'activitat de l'impressor.

Pel que fa a la descripció física, la $\mathrm{BC}^{37}$ només indica que l'exemplar té 94 pàgines i la $\mathrm{BNE}$ afig que té la portada orlada i el format és en octau. La BLM ens aporta informació nova pel que fa a la composició en 28 línies i reclams, a més de l’ornamentació floral de la darrera pàgina.

35 Gutiérrez del Caño (1899: 665) marca la seua activitat entre 1672 i 1735.

36 Com hem dit amunt la datació d'aquesta edició és provisional. Les referències bibliogràfiques que hem recollit són: Aguiló 2766, que indica que a la darrera pàgina s’hi veu «un jarro de flores del siglo XVII»; Miquel i Planas (1908: XX); Simón Díaz 7492; Palau, XIII, 225643, fixa l'edició al segle XVII.

37 Anotem les signatures de classificació de cada biblioteca on s'hi troben exemplars, junt amb l'escassa informació que en proporcionen: BC (860-3"16" Bon. 11-V-30); BNE (R/ 17702, enquadernació holandesa amb puntes; Cerv. Sedó/5776, enquadernació en pergamî); BMM (L146RES. V8862); BLM (840-3"11”, Fons Mata 260, exemplar incomplet perquè li falta el quadern A (p. 1-16); l'enquadernació en pergamí està desenganxada, taques d'òxid i d'humitat; segells de l'Ajuntament de Ripoll a f. 17 i 35).

SCRIPTA, Revista internacional de literatura i cultura medieval i moderna, núm. 7 / juny 2016 / pp. 52 - 69 ISSN: 2340-4841 $\cdot$ doi:10.7203/SCRIPTA.7.8055 
Rafel Figueró Delmunts (1642-1726) ${ }^{38}$ va treballar com a impressor i estamper a Barcelona des del 1668 fins el 1717. Casat amb una germana de Joan Jolis, va tindre un fill Rafael Figueró i Jolis (1669-1717), al qual, malgrat haver treballat tota la seua vida en el taller familiar, no se li pot atribuir cap peu d'impremta propi, perquè no va heretar el negoci familiar al premorir a son pare. Entre pare i fill van publicar uns 250 títols que, a més del Pierres, inclouen una reedició sense data del Partinobles. Pel que fa a la datació, aquesta pot abastar del 1668 fins al setge borbònic de Barcelona (1713-1714), quan es va cremar la impremta; al poc de temps, el 1717, va morir el seu fill. Entre unes coses $\mathrm{i}$ altres, la producció va anar en clar declivi i no es conserva pràcticament cap imprés posterior a aquest any. Amb tot, res no ens ajuda a solucionar aquest problema. Per tant, cal deduir que aquesta edició del Pierres degué imprimir-se al taller de Figueró entre 1668 i 1717, sense que puguem filar més prim fins a disposar de noves dades sobre la seua activitat impressora.

En terres gironines trobem les altres edicions del segle XVIII. La primera d'aquestes seria la impresa $^{39}$ a Olot, a càrrec de Josep Rovira. El títol és idèntic al de l'edició de Jolis, amb lleus canvis ortotipogràfics:

7) Rovira 1751-1764 La història del noble y molt esforsat cavaller Pierres de Provença, y de la gentil Magalona filla del Rey de Napols, y de les fortunes, y treballs, que passaren en lo temps de la sua enamorada vida. Tradubida de llengua castellana, en nostra Catalana, per lo discrét, y honràt Honoràt Comalàda. La informació general que ens dóna el registre complet de la BC -coincident amb el de la BLM- ${ }^{40}$ sobre aquesta edició és minsa: la data aproximada d'impressió obtinguda de Palau ens situa ca.1716; ${ }^{41} 125$ p., [3] p., $8^{\circ}, 15 \mathrm{~cm}$; reclams. Estampa xilogràfica a portada, caplletra ornamentació xilogràfica a l'inici de text, cul-de-llàntia xilogràfic a la p. 125 , vinyetes. Curiosament, encara s'hi atribueix l'autoria a Bernard de Treviers. La BMAR dóna una informació errònia perquè fa constar que està en italià i el data vers l'any 1700, sense lloc ni editor, perquè manca la portada.

La BC alberga tres exemplars d'aquesta edició. Sobre l'exemplar (15-II-43) ${ }^{42}$ se'ns dóna la següent descripció referent al seu estat de conservació:

38 Delgado (1996: 234-235) i Bohigas (1962: 224). La informació més completa, però, l'aporta Camprubí (2014: 516566), tot i no fer cap referència al Pierres, sí que ens permet delimitar més precisament una possible datació.

39 De nou ens trobem amb estimacions pel que fa a la data de l'edició. Referències bibliogràfiques: Aguiló 2768; Miquel i Planas (1908: XIX-XX); Simón Díaz 7494 dóna datació aproximada segle XVIII; Palau, XIII, 225644 -també li atribueix a Rovira una altra edició, segle XVIII, 225646.

40 BLM: Fons Mata 766. Aquesta és la informació sobre l'exemplar de Ripoll: enquadernació en pergamí, òxid, etiqueta de Lambert Mata a full de guarda i segells de l'Ajuntament de Ripoll a portada i p. 19.

41 Palau cita Miquel i Planas, però aquest no dóna cap data.

42 Les signatures dels altres exemplars són 11-V-47 i R(3)-8-14), però no donen cap descripció.

SCRIPTA, Revista internacional de literatura $i$ cultura medieval $i$ moderna, núm. 7 / juny 2016 / pp. 52 - 69 
Enquadernació en pergamí amb restes de tanques. Exemplar incomplet: falta l'últim full. Presenta taques d'òxid, d'humitat i algunes de tinta. El full de guarda anterior està estripat. L’ex-libris "Catalunya en el món de la família Porter-Moix" al contraplà anterior, ex-libris ms.: Narcís Albert Teixidor de la Bila de Bisbal 1796 Dia 14 Agost al full de guarda posterior, i un altre al contraplà anterior amb l'ex-libris de la família Porter-Moix adherit al damunt. Pertany al fons Joan Salvat.

El segon exemplar disponible a la BC és especialment interessant quant al problema de l'any de publicació perquè ens aporta una data ante quem: 1764. L'ex-libris manuscrit que trobem a la guarda del llibre diu: «Aquest llibre es de Cayetano Oliva parxer de Barcelona y lo comprà en dita en lo mes de 9bre. del añ 1764».

Miquel Puig i Reixach (2008) detalla uns quants fets cabdals en la vida de Josep Rovira que ens permeten descartar la data de 1716 establerta per Palau: Rovira arriba a Olot des de Girona el 1731; el 1740 s'estableix com a llibreter, i el 1751 apareix un fullet en llatí per a l'oració anual de santa Caterina amb el seu primer peu d'impremta. L'impressor mor el $1757 \mathrm{i}$ el seu fill homònim comparteix les tasques del taller en vida de son pare i les continua fins a la seua mort en 1771 . Aleshores, sembla evident que aquest Pierres de Provença cal situar-lo entre 1751 i 1764. El peu d'impremta diu que Josep Rovira és estamper i llibreter. El tercer exemplar no té característiques remarcables.

L'altra edició ${ }^{43}$ que va traure el taller de Josep Rovira de 94 p. en octau no la podem datar respecte d'aquesta que acabem d'esmentar però sí que sembla lògic suggerir la següent datació:

8) Rovira 1751-1771 La historia del noble, y esforsat Cavallèr Pierres de Provença, y de la gentil Magalona, filla del Rey de Napols, y de las fortunas y treballs que passaren en la sua molt enamorada vida. Trad[ubida] de llengua Castellana, [en] la nostra Cathalana, p[er] lo discret, y honràt Honoràt Comalàda. Té un peu d'impremta diferent: no n'especifica l'ofici, però sí la ubicació del taller dins el poble d'Olot: «En Casa Joseph Rovira, al Carrer Majón». ${ }^{44}$ Es tracta d'un text sense data -s'indica només segle XVIII- en octau, de 94 pàgines. Només se n'ha pogut localitzar un exemplar a la Biblioteca de la Universitat de Tolosa de Llenguadoc, d'on obtenim aquesta informació: la coberta de pergamí està foradada; la portada, ornamentada però no il lustrada com totes les suara vistes a excepció feta de la de Figueró, està deteriorada i presenta algunes taques humitat. A l'exemplar li manquen les pàgines 49 i 50, molt probablement obra d'alguna mà censora que va voler "deturpar" la història eliminant l'únic passatge eròtic que hi podem trobar. El colofó floral és idèntic. Es tracta, en conjunt, d'una edició més descurada que l'anteriorment descrita. Res no ens permet afirmar quina de les dues edicions olotines va antecedir l'altra.

43 Aguiló 2769, Simón Díaz 7492 i Palau 225646.

44 A l’inventari de la botiga de Josep Rovira fill el (26-2-1771) hi ha una referència a «catorse Pierres y Magalona».

SCRIPTA, Revista internacional de literatura i cultura medieval i moderna, núm. 7 / juny 2016 / pp. 52 - 69 
Palau Dulcet recull una altra edició -no vista- del 1718 a Olot a càrrec de l'impressor Ramon Roca. Aquesta darrera data és també errònia perquè Ramon Roca i Rovira, nebot de Josep Rovira, va nàixer en $1757 \mathrm{i}$ no va publicar cap Pierres. ${ }^{45}$

Al segle XVIII encara hi hauria dues edicions més, a Girona capital, al taller de Jaume Bro. Per a les dues proposem una datació aproximada, deduïda del període d'activitat de l'impressor:

9) Bro 1703-1768 La bistoria del noble, y esforsat Cavaller Pierres de Provença, y de la gentil Magalona filla del Rey de Napols, y de les fortunes y treballs que passaren en la sua molt enamorada vida. Tradubida de llengua castellanà, en la nostra Catalana, per lo discret, y honrat Honorat Comalada. De la primera, suposadament de $1733,{ }^{46}$ únicament podem aportar aquesta informació que consta en la fitxa de l'exemplar conservat a la BNE. Encara se li atribueix l'autoria a Treviers i es dubta sobre la data de publicació, entre 1733 i 1746, anys de l'activitat editorial de Jaume Bro. La descripció física ens diu que es tracta d'un únic exemplar de 40 pàgines, amb il lustracions, en quart [20 cm]. A l'altre exemplar ${ }^{47}$ d'aquesta edició, conservat a la $\mathrm{BC}$, se li atribueix la data aproximada del $1763^{48}$ i pertany a la Col lecció BonsomsChacón (Bon. 9-II-26). La descripció física d'aquest altre exemplar és: 40 pàgines, octau, $20 \mathrm{~cm}$. Té un gravat a la portada, amb frisos i caplletres ornamentades, reclams, enquadernat en pell amb daurats, i presenta taques d'òxid. L'exemplar de l'Ateneu Barcelonès no aporta res de nou i el de la BNA té l'inconvenient de no estar mínimament descrit pel que fa a paginació i format.

Sobre l'impressor Jaume Bro cal dir que pertany a una nissaga francesa d'impressors que havia intentat establir-se prèviament, sense èxit, a Barcelona. ${ }^{49}$ Jaume Bro està actiu a Girona entre $1703 \mathrm{i}$ 1768 -aquestes dates no coincideixen amb les aportades per la BNE - a la seua botiga instal lada al carrer Ballesteries, i encara vivia el 1776. De nou Mirambell (1984: 55-71) ${ }^{50}$ ens aporta informació

45 Miquel Puig inclou en el seu article un apèndix titulat "Repertori bibliogràfic dels impressors olotins del segle XVIII" (p. 50-62) on recull les dues edicions de Josep Rovira, però no hi consta cap de Ramon Roca.

46 Segons M.Llanas (2003: 162) cap de les dues edicions que va fer Jaume Bro té data. Les referències bibliogràfiques són: Aguiló 2765 -indica que el gravat de la portada mostra «un caballero y una dama del siglo XVI en traje de ceremonia»; Miquel i Planas; Simon Díaz 7491, s.d.

47 Hi ha d'altres exemplars d'aquesta edició: el de la Biblioteca Nacional d'Àustria atribuït a Bro i Girona, però sense data; el de la Biblioteca de Montepeller pertany a l'altra edició feta en octau de 112 pàgines, igualment sense data; el de l'Ateneu Barcelonès està datat ca. 1763, deduïda de l'època de treball de l'impressor.

48 Referències bibliogràfiques: Aguiló 2767 s.d.; Miquel i Planas (1908:XX); Simón Díaz 7493; Palau, XIII, 225645, fixa com a data el segle.

49 Mirambell (1984: 255). Gutiérrez del Caño (IV, 78) dóna la seqüència cronològica -inexacta pel que sabem per Camprubí- del membres de la nissaga Bro: Gabriel Bro 1705-1733, Jaume Bro 1733-1746 i Josep Bro 1761-1766.

50 Recull un inventari dels béns cedits per Jaume Bro al seu fill Josep on es parla de 25 còpies del Pierres de Provença i 125 del Partinobles. A més hi apareixen títols del mateix gènere com ara Historia de Don Pedro de Portugal, la Donzella Teodora,

SCRIPTA, Revista internacional de literatura i cultura medieval i moderna, núm. 7 / juny 2016 / pp. 52 - 69 
ben profitosa sobre els títols que omplien les prestatgeries de la seua impremta: hi van sortir dues edicions del Pierres (40 p. 4t i 112 p. $8^{\circ}$ ), igual que del Partinobles. ${ }^{51}$

10) Bro 1703-1768 La historia del noble, y esforsat Cavaller Pierres de Provença, y de la gentil Magalona filla del Rey de Napols, y de les fortunes y treballs que passaren en la sua molt enamorada vida. Tradubida de llengua castellanà, en la nostra Catalana, per lo discret, y honrat Honorat Comalada. Sobre la segona edició que va fer $\mathrm{Bro},{ }^{52}$ de 112 pàgines en octau, la $\mathrm{BNE}$ informa que a la portada hi ha un gravat xilogràfic; ni la $\mathrm{BNA}^{53}$-com ja s'ha indicat- ni la BMM aporten cap informació. Per tant, sembla evident que a hores d'ara no podem fer altra cosa que donar per vàlida qualsevol data entre 1703 i 1768 per ambdues edicions, sense saber quina va precedir l'altra. ${ }^{54}$

Fins ací arriba el cens del que podem anomenar edicions antigues del Pierres de Provença, concentrades en cent cinquanta anys, entre Barcelona, Olot i Girona.

\section{Segles XIX i XX}

Les peripècies del nostre cavaller i la seua dama no van deixar d'interessar al públic lector català, tot i que en castellà, llengua en què es van editar a la ciutat de Barcelona els anys 1818, 1836 i 1876 (Babbi 2003: 279). Després de les dues edicions gironines, el Pierres en català hiverna ${ }^{55}$ durant més de cent anys, fins que el 1895 Antoni Bulbena i Tusell ${ }^{56}$ fa una transcripció manuscrita del text, lleugerament canviat, a partir probablement de la primera edició de Josep Rovira:

11) Bulbena 1895 Història del noble e sforçat cavaller Pierres de Provença e de la gentil Magalona, filla del Rey de Näpols, e de les fortunes e treballs que passaren en la sua molt enamorada vida. Tradubida de llenga castellana en la nostra catalana per lo discret e honrat Honorat Comalada. Novament ordenada per A.B. $e$ T. 1895. L'únic exemplar que hem trobat és el de la $\mathrm{BC}$ (ms.1240 - Bul.125). Té 90 pàgines, 16 cm i presenta enquadernació holandesa, i consta com una transcripció i adaptació del text imprés. Així llegim al colofó: «Fonch acabada de transcriure la present historia de Pierres e de la gentil Magalona, e per Antoni Bulbena-Tusell un xich ordenada, en lo darrer díe del mes de Març del any 1895». Un acarament de la seua transcripció amb les edicions que coneixem ens permet afirmar

Robert el Diable, Clamades, etc.

51 També hi apareixen altres títols de novel la cavalleresca breu en català i en castellà.

52 Referències bibliogràfiques: Aguiló 2767, Miquel i Planas, Palau 225646, Simón Díaz 7493.

$53 \mathrm{La}$ BNA em va confirmar que es tracta d'un únic exemplar amb dues entrades distintes en la base de dades.

54L'exemplar de la BNE té una anotació del propietari on consta que va comprar el llibre l'1 de maig de 1771.

55 El Pierres de Provença també té una vida paralel la en castellà durant el segle XVIII (M.Llanas (2003: 171).

56 Bulbena (1854-1946) fou editor, escriptor i lexicògraf; publicà textos medievals catalans en edicions populars.

SCRIPTA, Revista internacional de literatura i cultura medieval i moderna, núm. 7 / juny 2016 / pp. 52 - 69 
que va fer tota una sèrie d'esmenes de forma sistemàtica a partir de textos diversos i de les normes ortogràfiques vigents a les acaballes del segle XIX i del seu propi gust.

Per tant, per a llegir la primera edició moderna, i la darrera fins ara, que s'ha fet en català, ens caldrà esperar al segle XX:

12) Miquel i Planas $1908^{57}$ El seu Pierres de Provença apareix dins el volum V de la sèrie Històries d'altre temps ("Textes catalans antichs, triats entre les produccions de caràcter novelesch escrites en la nostra llengua o en ella tradubides durant els segles XIV a XVII”). El subtítol que duu és el següent: Ara novament publicada segons les edicions de 1616? y 1650 per R. Miquel y Planas. Barcelona 1908. I el colofó editorial: Aquesta nova edicio catalana del Pierres de Provença fou acabada d' estampar el dia xxxj d'agost de l'any M. dcccc. viji per Mestre Fidel Giro de Barcelona a cura i despeses d'En Ramon Miquel y Planas, bibliofil. Les característiques físiques són: XX +89 pag. 12,5 x 18,5cm, amb il lustracions-gravats, rústica. Miquel i Planas va fer una edició modernitzada a partir del text de 1650 millorant algunes lliçons no satisfactòries amb les del text incomplet de $1616^{58}$ que semblava ser més acurat. L'estudiós català hi practica una nombrosa sèrie d'intervencions -més de cent trenta- de les quals la part forta són inclusions de paraules de poc relleu o correccions de petits errors de lectura en l'edició del text fetes a partir de la primera edició de 1616, proposant una xifra força més reduïda de lectures alternatives quan creu que la lliçó és clarament incorrecta. A més Miquel i Planas respecta la divisió en capítols, manté l'estructura monolítica de paràgraf únic en cada un d'ells i inclou els mateixos gravats que l'edició original de 1650 -no sabem si alguns provenien de l'edició més antiga, tot i que les dues mostres que podem veure (1908: XVIII) no apareixen en la més moderna. L'edició aparegué reimpresa el mateix any dins el Novelari català dels segles XIV a XVIII / publicat en vista dels manuscrits y edicions primitives per R. Miquely Planas, en el segon volum junt amb el Paris e Viana, Carcer d'amor $i$ el Partinobles.

\section{Conclusions}

La catalogació de les obres produïdes en català al llarg de l'època moderna és un procés que, lluny d'esgotar-se, continua donant els seus fruits. És dins aquest marc on volem encabir la nostra investigació. L'escorcoll de catàlegs ha estat profitós per esclarir alguns aspectes de la història editorial del Pierres de Provença, una obra popular, de consum, amb poc interés per ser conservada a les biblioteques, però de contínua presència als inventaris de llibreters des del segle XVI al XVIII. Amb tot, atesa l'escassa producció de prosa profana en el període de l'època moderna, és força convenient de catalogar una de les poques obres que hi van circular. A hores d'ara sembla

57 Referència bibliogràfica: Palau, XIII, 225647 i 225648. De la segona afirma: «Con la misma composición tipográfica de la anterior, por lo tanto es la misma edición».

58 Miquel i Planas (p. XVII) anota que hi manca un terç del total segons la foliació del volum de 1616.

SCRIPTA, Revista internacional de literatura i cultura medieval i moderna, núm. 7 / juny 2016 / pp. 52 - 69 
que el nombre d'edicions existents és d'onze, ${ }^{59}$ de les quals tres (1616, 1670 i 1683) estan perdudes o no disponibles; a més sospitem amb fonament que alguna més se'n va publicar en el XVI. Les incògnites sobre les primeres edicions són moltes; fins i tot s'ha especulat sobre la possible existència d'un original català anterior. Hem tingut accés a totes les edicions ${ }^{60}$ disponibles de les quals tan sols les de 1650 (Cormellas), 1895 (Bulbena), 1908 (Miquel i Planas, dues impressions) -a més de la de Lacavalleria de 1683, que no hem pogut consultar- tenen data d'impressió indicada en els volums conservats; la resta malgrat les diferents datacions aportades per biblioteques i reculls bibliogràfics no deixen de ser purament aproximatives en aquest aspecte. És el cas d'una de les dues edicions de Lacavalleria, de les de Jolis, Figueró, Rovira en dues ocasions i Bro, també en dues ocasions. Aguiló datava aquesta de Lacavalleria el 1670; les de Jolis i Figueró només les podem situar entre finals del segle XVII i primeries del XVIII; no tenim cap data concloent per decidir en quin ordre col locar les de Rovira i les de Bro. Hem proposat noves datacions per a les edicions de Figueró i de Rovira a partir dels darrers estudis sobre la impremta als segles XVII i XVIII, com ara el de Xevi Camprubí (2014) que aporta unes dades biogràfiques per a ambdós impressors que ens menen a situar l'edició de Rafael Figueró entre 1668 i 1717, i la de Josep Rovira entre 1751 i 1771. Ens caldrien nous estudis sobre la vida i activitat d'aquests impressors per a poder proposar una cronologia més acurada. Sembla evident que o s'ha perdut informació valuosa que tenien a l'abast els autors dels primers catàlegs bibliogràfics o cal revisar la majoria de les referències que les biblioteques aporten.

Per una altra banda, destaquem l'alta volatilitat d'aquesta mena de literatura popular on hem d'incloure el Pierres de Provença del qual, malgrat les nombroses edicions i les tiratges superiors als mil exemplars, ens han pervingut menys de vint còpies de les edicions antigues, la major part accessibles actualment en línia. Les edicions més afortunades -sense comptar la de Miquel i Planas amb moltes còpies disponibles- són les de Figueró i la primera de Rovira amb cinc exemplars cadascuna, i les dues de Bro amb tres còpies respectivament. Els reptes són poder trobar algun exemplar de les edicions de 1616 de Cormellas i 1670 de Lacavalleria, així com tindre accés a la de 1683, del mateix impressor, en mans privades desconegudes. Per tant, de moment, el text base per a qualsevol edició crítica de la novel la ha der ser el que va imprimir Sebastià Cormellas a Barcelona el 1650, del qual només se'n conserva un únic exemplar a la Bibliothèque National de France (RÉS-Y2-710).

Les edicions de la novel la Pierres de Provença es van centrar en uns pocs tallers barcelonins i gironins, atés que no hem trobat cap referència a l'obra en cap altre indret del domini lingüístic català. La vida d'aquest producte editorial - elaborat per mitja dotzena d'impressors- abasta fonamentalment els segles XVII i XVIII, durant els quals una nombrosa massa lectora va gaudir d'aquesta interessant novel la breu que navega entre aigües de tonalitats ben distintes (cavalleresques, sentimentals, hagiogràfiques, etc.) oferint una lectura senzilla, amena i edificant.

59 Com hem dit abans, fem referència a la transcripció de Bulbena, però no la incloem en el cens de les edicions.

60 Quant als formats, es van imprimir en quart les de 1616 i 1650 de Cormellas, les dues de Lacavalleria, Jolis i la primera de Bro; la resta en octau.

SCRIPTA, Revista internacional de literatura i cultura medieval i moderna, núm. 7 / juny 2016 / pp. 52 - 69 ISSN: 2340-4841 · doi:10.7203/SCRIPTA.7.8055 


\section{Bibliografia}

Aguiló, M. (1923) Catálogo de obras en lengua catalana impresas desde 1474 hasta 1860, Madrid, Sucesores de Rivadeneyra.

Babbi, A. (ed.) (2003) Pierre de Provence et la Belle Maguelonne, Soveria Mannelli, Rubbettino.

Biblioteca de Catalunya: http://www.bnc.cat/Fons-i-col-leccions/Cerca- Fons-i-col-leccions/ Jolis-Pla-Impressors

Biblioteca de Montepeller: http://ccfr.bnf.fr/.

Biblioteca Nacional d'Àustria: http://www.onb.ac.at/

Bohigas, P. (1962) El libro español, Barcelona, Ensayos históricos.

Brunet, J.C. (1860-1865) Manuel du libraire et de l'amateur de livres, 4, París, Firmin Didot.

Biblioteca Virtual Miguel de Cervantes: http://www.cervantesvirtual.com/obra-visor/la-historiadel-noble-y-esforsat-cavallerpierres-de-provenca-y-de-la-gentil-magalona-filla-del-reydenapols-y-de-las-fortunas- $\mathrm{y}$ - treballs-que-passaren-en-la-sua-molt-enamorada-vida--0/html/

Camprubí, X. (2014) L’impressor Rafael Figueró (1642-1726) i la premsa a la Catalunya del seu temps, Universitat de Barcelona, Tesi doctoral.

Delgado, J. (1996) Diccionario de impresores españoles (siglos XV-XVII), 1, Madrid, Arco Libros.

Diccionari de literatura de la Enciclopèdia (2008), Barcelona, Enciclopèdia Catalana.

Gallardo, B. (1863) Ensayo de una biblioteca de libros raros y curiosos, 1. Madrid, Manuel Tello.

Garcia, M. / Wilkinson, A. (2011) "La producció impresa en català als ss. XV i XVI", Caplletra 51, pp. 51-79.

Gayangos, P. (1857) Libros de caballerías, Madrid, M. Rivadeneyra.

Gutiérrez, M. (1899) "Ensayo de un catálogo de impressores españoles desde la introducción de la imprenta hasta fines del siglo XVIII" Revista de archivos, bibliotecas y museos, 3a època, 3, p. 665669; IV, p. 78, Madrid, M. Rivadeneyra.

Infantes, V. (1989) 'La prosa de ficción renacentista: entre los géneros literarios y el género editorial', Journal of Hispanic Pbilology, 13-2, pp. 115-124.

Llanas, M. (2001) El llibre i l'edició a Catalunya: apunts i esbossos, Barcelona, Gremi d'Editors de Catalunya.

—. (2002) L'edició a Catalunya: segles XV al XVII, Barcelona, Gremi d'Editors de Catalunya.

—_. (2003) L'edició a Catalunya: el segle XVIII, Barcelona, Gremi d'Editors de Catalunya.

—. (2007) Sis segles d'edició a Catalunya, Lleida, Eumo Editorial/Pagès Editors.

Madurell, J. / Rubió, J. (1955) Documentos para la bistoria de la imprenta y librería en Barcelona (14741553), Barcelona, Gremio de Editores, de Libreros y de Maestros Impresores. 
Mateu, J. (1994) "Agustín Millares Carlo y las bibliotecas de Cataluña. Su estudio referente a obras impresas en Barcelona durante el siglo XVI", Boletin Millares Carlo, 13, Las Palmas de Gran Canaria, UNED, pp. 201-258.

Miquel i Planas, R. (ed.) (1908) Pierres de Provença, Barcelona, R. Miquel i Planas / Fidel Giró.

—. (1929), Ensayos de bibliofilia, 1, Barcelona, Casa Miquel Rius.

Miralles, E. (ed.) (2010) Del Cinccents al Setcents. Tres-cents anys de literatura catalana, Bellcaire d'Empordà, Edicions Vitel la.

Mirambell, E. (1984) "La família Bro, d'impressors gironins", Annals de l'Institut d'Estudis Gironins, 27, pp. 249-311, Girona, Institut d’Estudis Gironins.

- (1988), Història de la impremta a la ciutat de Girona, Girona, Institut d'Estudis Gironins.

Moliné, E. (1918) Llibreters barcelonins del segle XVII: Cabrit: Trinxer, Barcelona, Llibreria Antiga y Moderna de S.Babra.

Palau, A. (1961) Manual del librero hispanoamericano, 13, Barcelona, A. Palau.

Pascual. J. (1985) "Literatura e imprenta en la Barcelona del siglo XVII. (El caso de Antonio Lacavalleria)", El Crotalón, 2, pp. 607-639, Madrid, Pedro M. Cátedra.

Puig, M. (2008) “La impremta a Olot al segle XVIII", Annals del Patronat d'Estudis Històrics d'Olot i Comarca, 19, pp. 11-62.

Rodríguez, E. (1984) Romancero impreso en Cataluña, 1, Madrid, José Porrúa.

Rossich, A. (2010) "La narrativa catalana entre el Tirant i L'orfaneta de Menargues" dins Miralles, E. (ed.) Del Cinccents al Setcents. Tres-cents anys de literatura catalana, pp. 159-177, Bellcaire d'Empordà, Edicions Vitel la.

Roudaut, F. (ed.) (2009) Pierre de Provence et la belle Maguelonne, París, Éd. Classiques Garnier.

Rubió, J. (1985), Història de la literatura catalana, 2, Barcelona, Publicacions de l'Abadia de Montserrat. - (1993) Llibreters i impressors a la Corona d'Aragó, 11, Barcelona, L'Abadia de Montserrat.

Simón, J. (1954) Bibliografía de la literatura hispánica, III, vol. II, Madrid, CSIC.

Socias, I. (2001) Els impressors Jolis-Pla i la cultura gräfica catalana en els segles XVII i XVIII, Barcelona, Publicacions de l'Abadia de Montserrat.

Torres, F. (1836) Memorias para ayudar a formar un diccionario crítico de los autores catalanes y dar alguna idea de la antigua y moderna literatura de Cataluña, Barcelona, Jacint Verdaguer.

Valsalobre, J. / Rossich, A. (2011) Literatura i cultura catalanes (segles XVII i XVIII), Barcelona, Universitat Oberta de Catalunya.

Vila, P. (1999) "Manuscrits catalans a la biblioteca de la família Puiggarí de Perpinyà", Llengua \& Literatura, 10, pp. 317-328.

Wilkinson, A. (2010) Iberian Books, Dublín, Brill. 